\title{
Dilated Cardiomyopathy is a Risk in Junctional Epidermolysis Bullosa
}

\author{
Fatma Alzahraa Mostafa ${ }^{1 *}$, Hala Agha ${ }^{1}$, Ghada Anwar ${ }^{1}$ and Mohamed Rafie $^{2}$ \\ ${ }^{1}$ Department of Pediatric, Cairo University, Egypt
}

${ }^{2}$ Department of Pediatric, Alazhar University, Egypt

Submission: April 01, 2019; Published: April 24, 2019

*Corresponding author: Fatma Alzahraa Mostafa, Department of Pediatric, Pediatric hospital Cairo University, Egypt

\section{Introduction}

Epidermolysis bullosa (EB) is a group of genetic conditions that result in easy blistering of the skin and mucous membranes $[1,2]$. Blisters occurs with minor trauma or friction and are painful [1]. Its severity can range from mild to lethal [1]. Those with mild cases may not develop symptoms until they start to crawl or walk. Complications may include esophageal narrowing, squamous cell skin cancer, and the need for amputations. There are previous reports of dilated cardiomyopathy (DCM) and sudden death in recessive dystrophic epidermolysis bullosa (RDEB), a debilitating blistering skin disorder. The pathogenesis of DCM in RDEB remains uncertain, although dietary deficiency of selenium and carnitine have been implicated $[3,4]$.

\section{Case Report}

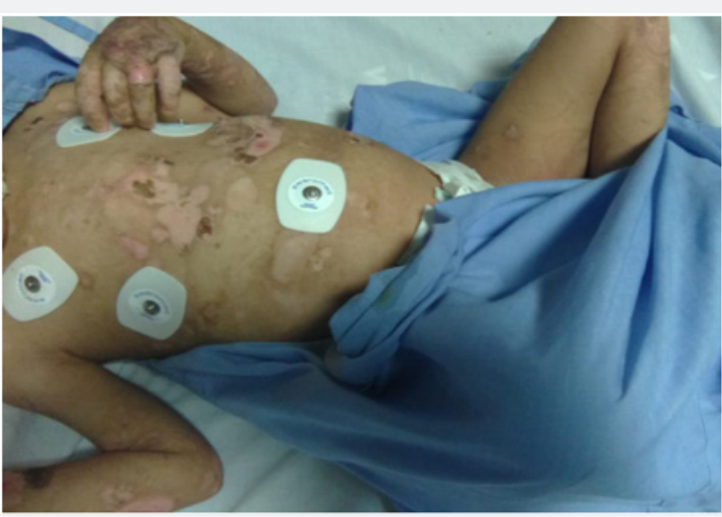

Figure 1: Cutaneous changes of EB patient.

We report a $3 y$ old male patient, His parents are consanguineous, He was diagnosed as junctional Epidermolysis Bullosa affecting both skin and mucous membranes with nail dystrophy and teeth affection, (Figure $1 \& 2$ ). He was admitted to hospital because of gradual onset and progressive onset dyspnia and fever. His condition started a week before. Pneumonia and congestive heart failure were diagnosed. Elevated CRP and leukocytosis, anemia (HB7gm\% HCT 23\%) are found, selenium level was $39.2 \mu \mathrm{g} / \mathrm{l}$, Chest X-ray revealed pneumonia and cardiomegaly (Figure 3). Echocardiography was requested. Echocardiographic examination revealed markedly dilated and myopathic left ventricle with FS 24\%, with severe mitral regurge. Troponin $\mathrm{T}$ level was not elevated so myocarditis is excluded, and dilated cardiomyopathy is the probable diagnosis. The patient received diuretics and captopril with adequate response within a week (Figure 4).

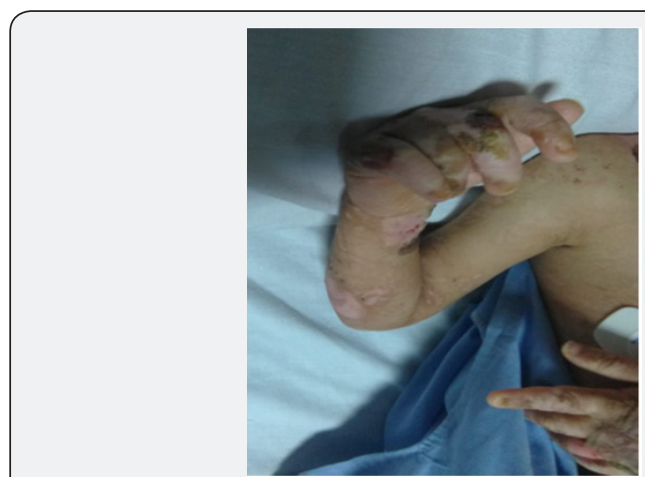

Figure 2: Cutaneous changes of EB patient.

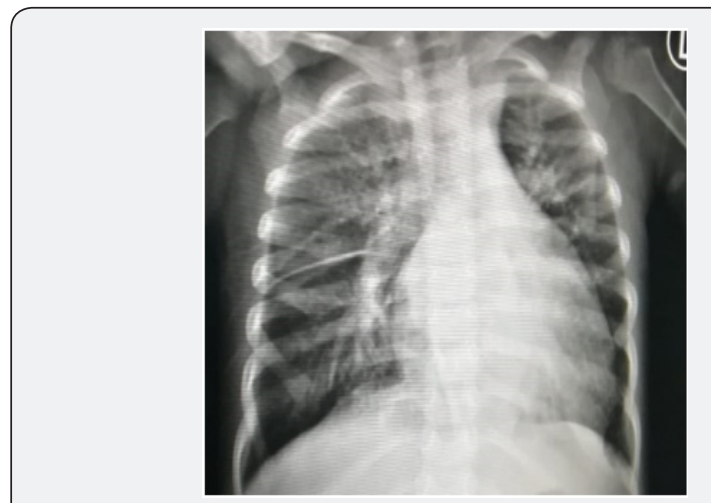

Figure 3: Chest x-ray of EB patient. 


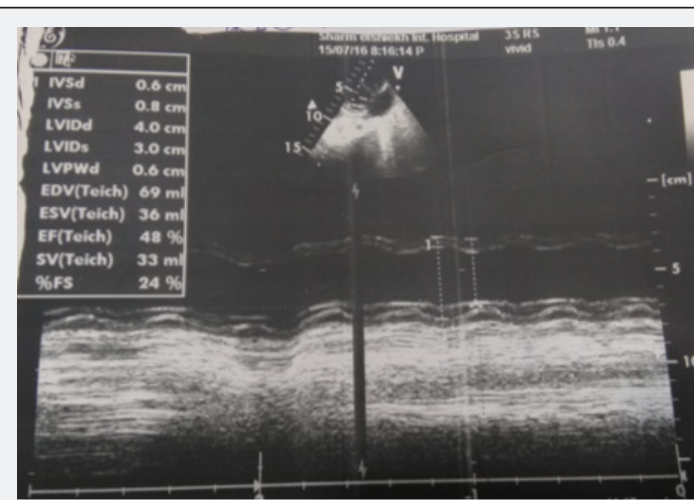

Figure 4: Echocardiographic assessed LV functions of EB patient.

\section{Discussion}

Some cases of EB are known to be associated with extracutaneous anomalies including pyloric atresia, obstructive uropathy [5] muscular dystrophy [6], dilated cardiomyopathy [7,8], renal amyloidosis [8] or osteoporosis [9], making EB a multi-systemic disease. Efforts therefore should be made to investigate the patient (including postmortem) for any associated anomaly. History of polyhydramnios with feeding difficulties, abdominal distention, non-bilious vomiting and large distended stomach on plain abdominal radiograph can suggest pyloric atresia while respiratory distress with significant cardiomegaly on chest radiogram, electrocardiography and echocardiography in an older child with blistering skin may indicate EB with dilated cardiomyopathy. Clinicians should also have a high index of suspicion in cases where there are blistering of the skin especially in the pediatric age group. Cardiomyopathy was reported as early as within the first year of life. In patients having no other known risk factors for CHF or cardiomyopathy, [10].

Our patient 1st presentation was at $3 y$ old and he has no other associated anomalies.

Our patient presented with anemia with HB level 7gm\%, HCT $23 \%$.

It is quite likely that chronic anaemia, a well-recognized cause of dilated cardiomyopathy, plays a clinically relevant role in the development of CHF and cardiomyopathy in severe generalized EB, particularly RDEB-HS. Consistent with that. Patients with
RDEB-HS may suffer from severe multifactorial anemia, although lack of data on hemoglobin levels at the time of onset or diagnosis of cardiac findings prevents any quantitative comparison between those patients with and those without CHF or cardiomyopathy $[11,12]$.

\section{Conclusion}

Dilated cardiomyopathy should be searched for in junctional EB.

\section{References}

1. Epidermolysis Bullosa (2018) National Institute of Arthritis and Musculoskeletal and Skin Diseases.

2. Tabor A, Pergolizzi JV Jr, Marti G, Harmon J, Cohen B, et al. (2017) Raising Awareness Among Healthcare Providers about Epidermolysis Bullosa and Advancing Toward a Cure. J Clin Aesthet Dermatol 10(5): 36-48.

3. Brook MM, Weinhouse E, Jarenwattananon M, Nudel DB (1989) Dilated cardiomyopathy complicating a case of epidermolysis bullosa dystrophica. Pediatr Dermatol 6: 21-23.

4. Morelli S, Dianzani C, Sgreccia A, Porciello R, Bottoni U, et al. (2001) Reversible acute global left ventricular dysfunction in a patient with autosomal recessive dystrophic epidermolysis bullosa. Int J Cardiol 79(2-3): 321-323.

5. Bauer J, Schumann H, Sonnichsen K, Tomaske M, Bosk A, et al. (2002) Molecular diagnostics facilitate distinction between lethal and nonlethal subtypes of junctional epidermolysis bullosa: a case report and review of the literature. Eur J Pediatr 161(12): 672-679.

6. Horn HM, Tidman MJ (2000) The clinical spectrum of EBS. Br J Dermatol 142(3): 468-472.

7. Sidwell RU, Yates R, Atherton D (2000) Dilated cardiomyopathy in dystrophic epidermolysis bullosa. Arch Dis Child 83(1): 59-63.

8. Kaneko K, Kakuta M, Ohtomo Y, Shimizu T, Yamashiro Y, et al. (2000) Renal amyloidosis in recessive dystrophic epidermolysis bullosa. Dermatology 200(3): 209-212.

9. Kawaguchi M, Mitsuhachi Y, Kondo S (1999) Osteoporosis in patient with RDEB. B J Dermatol 141: 934-935.

10. Fine JD, Hall M, Weiner M, Li KP, Suchindran C (2008) The risk of cardiomyopathy in inherited epidermolysis bullosa. Br J Dermatol 159(3): 677-682.

11. Paulson DJ (1998) Carnitine deficiency-induced cardiomyopathy. Mol Cell Biochem 180(1-2): 33-41.

12. Kanekura T, Yotsumoto S, Maeno N, Kamenosono A, Saruwatari H, et al. (2005) Selenium deficiency: report of a case. Clin Exp Dermatol 30(4): 346-348. 


Your next submission with Juniper Publishers
will reach you the below assets
- Quality Editorial service
- Swift Peer Review
- Reprints availability
- E-prints Service
- Manuscript Podcast for convenient understanding
- Global attainment for your research
- Manuscript accessibility in different formats
( Pdf, E-pub, Full Text, Audio)
- Unceasing customer service
Track the below URL for one-step submission
https://juniperpublishers.com/online-submission.php

